


\section{ORGANIZATIONAL ROUTINES}

Organizational routines have been viewed in two different but related ways: (1) as patterned behavior or activity (Nelson \& Winter, 1982) or (2) as rules, procedures, or recipes that are executed in carrying out a particular behavior or activity (Becker, 2004). In the closely related literature on capabilities, a capability is defined as a collection of routines (Winter, 2003) that provides the capacity to perform an activity for an intended purpose (Amit \& Schoemaker, 1993; Helfat, Finkelstein, Mitchell, Peteraf, Singh, Teece, \& Winter, 2007). That is, routines provide the potential to undertake an activity rather than constituting the activity itself (Helfat et al., 2007). Consistent with this definition and the definition of routines in Becker (2004), we use the term "routine" to mean a procedure that in turn provides the potential for an organization to undertake an activity.

A routine, in the sense of a procedure, consists of a series of steps for executing a task or activity. Similar terms include "blueprint" or "rules" or "standard operating procedure" for executing an activity. A routine can also be viewed as a recipe that specifies the ingredients required for an activity, such as particular resources and assets, in addition to the steps needed to combine or otherwise utilize the resources for an intended outcome. Of note, such procedures can be tacit and implicit as well as codified and explicit. Indeed, a key feature of routines is their often tacit nature (Winter, 1987).

Our interest here is in organizational routines as opposed to routines of individuals. Organizational routines involve teams or sets of teams that perform activities within functional areas (e.g., manufacturing) or across functional areas (e.g., cross-functional product design). Because organizational routines involve multiple individuals that interact, routines include mechanisms for coordination between individuals, teams, and groups (see also Becker, 2004). Also, routines are specific to the organizational activities or tasks that they support. This specificity has at least two important aspects. The first has to do with the intended purpose of the routines and the capabilities they support. The second has to do with the context-dependent nature of routines. We next discuss each of these in turn.

\section{Operational Versus Dynamic Purposes of Routines}

With regard to the intended purpose of capabilities and their associated routines, both Winter (2003) and Collis (1994) distinguished between zero-order and first-order capabilities. Winter (2003) termed these operational and dynamic capabilities, respectively. The former denote capabilities directed toward maintaining how an organization earns its living "by producing and selling the same product, on the same scale and to the same customer population over time" (Winter, 2003: 992). In contrast, first-order or dynamic capabilities are directed toward changing "the product, the production process, the scale, or the customers (markets) served" (Winter, 2003: 992). Winter, in Murmann et al. (2003), has used the term "operational routines" to denote routines that underpin operational capabilities. These routines and the capabilities that they support are directed toward ongoing activities that are conducted in more or less the same way each time (Helfat \& Winter, 2011). Additionally, routines that underpin dynamic capabilities can be thought of as "dynamic routines." Such routines include those involved in planning, initiating, and implementing change, ranging from investments in plant and equipment and new product development to strategic assessments and planning for strategic initiatives such as market entry. As Helfat and Winter (2011) have noted, the line between operational and dynamic capabilities - and, by implication, between operational and dynamic routines - is inevitably blurry. Nevertheless, they argue that the distinction serves a useful purpose of highlighting that some routines and capabilities are oriented more toward change and others are oriented more toward maintaining the status quo.

\section{Context Specificity of Routines}

By their nature, routines are also context-specific. As Winter observed in Murmann et al. (2003: 28), there are "diverse solutions to the same basic task or problem in a collection of organizations." Consider a routine for assembling the parts of a car. Although the broad outlines of a routine for car assembly may be the same for any company in any plant in any 
location for any automobile model, the details of the routine will vary according to these characteristics. Different car models use different components that may need to be assembled in different ways; assembly plants in different geographic locations may be configured in different ways, to which the assembly routines are then tailored; and different companies may have histories of different assembly routines that persist over time. These differences in routines across settings often arise from different starting points in combination with local search as organizations learn over time (Helfat, 1994).

The fact that routines develop through learning (Zollo \& Winter, 2002) is a particularly important determinant of context specificity (Becker, 2004). A great deal of organizational learning comes from experience-from learning-by-doing and learning-by-using (Argote, 1999). Almost by definition, all experience is context-specific to some extent. That is, what a team of individuals learns depends on the context in which the learning takes place. To return to the assembly plant example, when a team of individuals learns a job on the assembly line, what they learn depends on the configuration of the particular plant, the components of the particular automobile model, and the routines typically used in the organization. Even learning that involves gaining an understanding of codified information is likely to be tailored to a particular setting. Thus, if assembly line workers receive written instructions about how to perform their jobs, they are likely to need to tailor these instructions to the idiosyncrasies of the production line in question. As a consequence, Feldman and Pentland (2003) argue that routines evolve as individuals amend them in a particular setting.

Management scholars have examined context specificity in various ways. For example, the organizational ecology literature has emphasized that firms and their structures become adapted to their external environments, either as generalists serving a mass market or as specialists serving a market niche (Hannan \& Freeman, 1989). In addition, the resourcebased literature in strategy often emphasizes the firm-specificity of resources and capabilities (Barney, 1991). Others in this research stream have noted that resources and capabilities (such as managerial skills) are often specific to particular industries (e.g., Castanias \& Helfat, 1991).

Capabilities and the routines that support them, however, may vary not only across organizations, but also within them. That is, even within firms, routines of a particular type - such as for assembling a car-may differ, including by location or type of product. Szulanski $(1996,2003)$ has demonstrated that firms face numerous obstacles when seeking to transfer routines internally across locations and business units. In addition, Rumelt (1991) and McGahan and Porter (1997) have shown that the largest portion of the variation in profitability resides at the business-unit level, suggesting that there are "cross-sectional differences and persistence in the way things happen at the plant level, say, or at the business unit level" (Winter in Murmann et al., 2003: 28). Thus, Pentland and Feldman (2005: 796) have observed with reference to hiring routines that: "Even within a single organization, there may be endless variations on the appropriate way to go about hiring people for different kinds of jobs, in different departments, or at different times of year." That is, "no two routines are really the same" (Winter in Murmann et al., 2003: 30, italics in the original). In what follows, we examine in more detail how routines may differ across business units within multidivisional firms and the potential sources of business-unit specificity in routines.

\section{ORGANIZATION DESIGN AND ORGANIZATIONAL ROUTINES}

In order to assess how routines may differ across business units, we must first understand where firms draw boundaries between business units and how they manage those units. This involves two key aspects of organization design on which we focus here and which have traditionally been associated with the issue of centralization versus decentralization within organizations: (1) division of tasks and (2) the extent of delegation in decision-making authority. With regard to the division of tasks, we focus on the relationship between the extent of task independence and the extent of modularity in organizational structure. With regard to delegation of decision-making authority, we focus on the extent of top management team involvement in business-unit decisions. 


\section{Modularity and Separation of Tasks in Organization Design}

Organization design scholars have studied the evolution of firms and their structures, and noted their growth from single-business to multi-business entities. Much of the work in classic organization design has examined the multidivisional form (Chandler, 1962) and the separation of market activities into different divisions or units (Galbraith \& Kazanjian, 1986; Mintzberg, 1979; Nadler \& Tushman, 1997). Mintzberg (1979: 325) describes organizational "superstructures" as grouped into units according to either function ("by the means the organization uses to produce its products or services") or market ("by ends, by the characteristics of the ultimate markets the organization serves"). How much of the "means" or "ends" are grouped together — or what is referred to as unit size - is determined by the level of coordination required across the work processes; such coordination depends on the interdependencies in workflow, scale, and social relationships (Mintzberg, 1979).

Based on the concept of interdependence that is highlighted in both classic organization design (Galbraith, 1977; Lawrence \& Lorsch, 1967; Thompson, 1967) and complexity theory (Alexander, 1964; Kauffman, 1991, 1992; Simon, 1996; Weick, 1976), scholars such as March and Simon (1958) and Thompson (1967) proposed that tasks that are highly interdependent (tightly coupled) should be carried out within the same organizational unit, because the work requires coordination or benefits from integration. Conversely, the greater the extent to which tasks are loosely coupled or differentiated, the more the tasks can be carried out by independent units. Scholars later developed a modular systems theory that applied to organizations (Baldwin \& Clark, 2000; Sanchez \& Mahoney, 1996; Schilling, 2000), and incorporated similar arguments regarding the separation of tasks, processes, or components into organizational modules.

\section{Business-Unit Specificity of Routines}

To benefit from the grouping of tasks (or work in general) within units, organizations require coordination and integration of these tasks. This naturally leads to the question of which coordination and integration mechanisms create benefits from grouping activities together. In an examination of the reconfiguration of product-market activities simultaneously with their respective business units, Karim (2012) introduced the idea of "structural embeddedness" to refer to "the activities and resources that reside within a structural context and have some dependence upon this contextual environment to create value" (Karim 2012: 333). She proposed that the dependence comes from established "contextual links" that "represent coordination mechanisms applied to activities that may embed activities and their underlying resources within their business units" (2012: 333).

We argue that these coordinative, contextual links stem from routines that are specific to the business unit. In other words, to effectively integrate tasks and complete work, organizational units depend on the business-unit specificity of routines. Building on Galbraith and Kazanjian's (1986) "integrating mechanisms" (which include allocating resources, measuring performance, and selecting and developing managers), we argue that these mechanisms involve routines that are specific to the context in which they are applied. Examples of contexts that are likely to have business-unit-specific routines include particular products or services, operations or functions, technologies, geographic locations, institutional settings, and stages in the value chain.

To return to the example of automobiles, we expect that a business unit focused on the functions of monitoring and coordinating fuel efficiency and car emissions would have specific routines to identify, evaluate, and obtain the resources needed to effectively complete these tasks. These routines are likely to be specific to this business unit, such that tasks in another unit performing different functions would have less need of, or dependence upon, these routines. We would further expect that the allocation of resources (including the manager selected to lead a particular unit) may depend on the geographic or institutional constraints faced by the business unit. If the unit faces stringent emission standards from a particular region or governing body, the unit may have routines not only to help measure emissions and fuel efficiency performance, but also to interact (with the right people and through specific processes) with the necessary institutions. We would not expect other units 
to necessarily deploy the same emissions performance routines and routines of interchange with regulators - or at least not to the same extent. Thus, to effectively complete its task of building cars to meet minimum fuel efficiency and emissions standards, the organization depends on business-unit-specific routines within the unit that coordinates this type of work.

By definition then, business-unit-specific routines, and what Karim (2012) has referred to more broadly as "contextual links," imply some level of context dependence between tasks and routines. Over time, routines that coordinate the specific tasks that are grouped within an organizational unit become embedded in that unit. If another business unit were to suddenly take over responsibility for these tasks, the unit's routines would not be as well matched to the context, and the tasks would not be completed as effectively (Karim, 2012). As a consequence, we expect that units with greater business-unit specificity of routines will create more value by keeping the associated resources and activities embedded in their structures than by dislodging these tasks to other parts of the organization.

\section{Delegation of Authority and Top Management Team Involvement}

As discussed above, when tasks are independent, firms can utilize a modular organizational structure. This implies that decision making can be pushed lower down in the organization, because upper-level management need not coordinate the transfer or sharing of resources between business units on an ongoing basis. In a review and assessment of a great deal of literature on diversification, Hill, Hitt, and Hoskisson (1992) argue that when business units operate independently, firms not only can delegate decision-making authority to individual units but also can provide more high-powered incentives to business unit executives based on the profitability of their divisions (see also Williamson, 1985). Under this arrangement, top management oversight of business units is limited to financial controls based on quantitative metrics. In contrast, greater business-unit interdependence calls for greater top management involvement in coordination across units. Michel and Hambrick (1992) further note that the capacity for intra-firm coordination depends in part on the composition of the top management team (TMT). In particular, collaborative skills, breadth of perspectives, and shared backgrounds of the top management team improve the ability of the team to manage interdependent business units (see also Galbraith, 2010).

\section{Operational Routines and Top Management Team Involvement}

Although much research has investigated the relationship between the extent of business-unit interdependence and the extent of top management involvement in the business units, almost no research has investigated the relationship between organizational routines and the extent of top management involvement in business units. Because routines by definition promote predictable activity, this might suggest that organizations with well-developed routines require less top management involvement in business units. However, this conclusion may not hold for all types of routines. In particular, when examining the relationship between routines and top management involvement in the business units, it is useful to distinguish between operational and dynamic routines.

As noted earlier, operational routines are directed toward performing operations in much the same way as in the past for the same market and customers. Such routines maintain the status quo, and when these routines function well, their utilization within business units should not require intervention by the top management team. For example, absent technological, market, product, or customer change, the auto assembly routines in the example given earlier should not require top management intervention. Even operational routines that involve coordination between (rather than within) business units, such as routines involved in coordination of internal supply chains across units, do not call for extensive involvement of top management. These operational cross-unit coordination routines may involve the use of lateral linkages such as information technology (for budgeting or sourcing processes), crossunit groups, or liaison roles (Nadler \& Tushman, 1997). Nevertheless, operational routines for coordination between business units may call for some top management attention to ensure that coordination between business units does not lapse. Without such attention, business units may tend to focus on their own operational tasks rather than on those that involve other 
units. Thus, we expect that operational routines that span business units will have greater top management involvement than operational routines that are specific to individual business units.

\section{Dynamic Routines and Top Management Team Involvement}

In contrast to operational routines, dynamic routines are directed toward changing how a company makes its living, including by changing operational routines. Because dynamic routines involve organizational and strategic change, at first glance it may appear that such routines call for greater involvement of the top management team. However, some types of dynamic routines may call for more top management team involvement than others.

As an example, consider dynamic routines for choosing specific innovation projects in pharmaceutical drug discovery research. Different medical conditions (e.g., heart disease versus cancer) may involve different considerations for which avenues to pursue next and therefore may entail different criteria and routines for choosing research projects. Such routines need not involve the top management team if they affect only the individual business rather than the firm as a whole and do not require a firm-level strategic perspective. Under these conditions, personnel within the businesses are likely to have much better information and expertise to carry out these narrow business-specific routines. Personnel positions are usually grouped into business units based on expertise with respect to skill, knowledge, specific work process, business function, product, client, or place (Mintzberg, 1979). Thus, dynamic routines that affect only the business unit, and for which top management has no additional, relevant expertise, are likely to be carried out by business unit personnel without top management intervention.

Other dynamic routines call for greater top management involvement in coordination within the firm, such as with respect to innovations that span multiple businesses or functional areas. For example, "design-for-manufacture" involves coordinated design of new products and manufacturing processes. Because this requires cross-functional coordination, the procedures for such coordination are likely to be put in place and monitored by top management and corporate-level staff. Because these innovations also call for a firm-level rather than a business-unit perspective, top management and corporate staff are likely to be directly involved in overseeing the innovation process, and are likely to have routines for managing this oversight.

More generally, some dynamic routines may reside within the top management team itself (Karim \& Williams, 2012), complemented by routines of corporate staff units responsible for implementing strategy. To echo Rumelt's (1974: 20) early argument, "general management must view the firm as a whole" when considering changes in operations and resource allocation that go beyond single business units. In essence, their job is "to provide integration at a broader level of policies and strategies" (Lawrence \& Lorsch, 1967: 56). The findings of Michel and Hambrick (1993) and Galunic and Eisenhardt (1996, 2001) apply here as well: such dynamic routines may call for top management teams with the breadth of perspective, cohesion, and collaborative skills necessary to effect change within an organization. Thus, we expect that dynamic routines that affect multiple business units or that are specific to individual business units but can benefit from top management expertise will require greater top management involvement than operational routines.

In summary, both the extent of task interdependence and the nature of routines have implications for the appropriate extent of top management team involvement in business unit decisions. Some routines, like the tasks and activities that they support, can be delegated entirely to the business units; others call for top management involvement. In what follows, we bring together the analysis of task interdependence, top management team involvement, and the characteristics of organizational routines to propose a framework for understanding organization design-routines fit. 


\section{ORGANIZATION DESIGN-ROUTINES FIT}

Figure 1 summarizes the framework for organization design-routines fit. In this two-by-two matrix, the vertical axis distinguishes between operational and dynamic routines, and the horizontal axis distinguishes between high and low business-unit specificity of routines. Although the dividing line between operational and dynamic routines is blurry (Helfat \& Winter, 2011), and there is a continuum of the extent of business-unit specificity of routines, for purposes of exposition we utilize a two-by-two diagram. In each quadrant of the diagram, we indicate the likely extent of organizational modularity and top management involvement with the business units.

\begin{tabular}{|c|c|c|}
\hline \multirow{2}{*}{$\begin{array}{c}\text { Operational } \\
\text { Routines }\end{array}$} & $\begin{array}{c}\text { Quadrant 1 } \\
\text { Less Modular Design } \\
\text { Low-Medium TMT Involvement }\end{array}$ & $\begin{array}{c}\text { Quadrant 2 } \\
\text { More Modular Design } \\
\text { Low TMT Involvement }\end{array}$ \\
\cline { 2 - 3 } $\begin{array}{c}\text { COORDINATED STATUS QUO } \\
\text { Dynamic } \\
\text { Routines }\end{array}$ & Quadrant 4 & MODULAR STATUS QUO \\
\hline & $\begin{array}{c}\text { Medium-High TMT Involvement } \\
\text { Less Modular Design }\end{array}$ & $\begin{array}{c}\text { Quadrant 3 } \\
\text { Low TMT Involvement }\end{array}$ \\
\cline { 2 - 3 } & COORDINATED CHANGE & Modular Design \\
& $\begin{array}{c}\text { Low } \\
\text { Business-Unit Specificity of } \\
\text { Routines }\end{array}$ & $\begin{array}{c}\text { Musiness-Unit Specificity of } \\
\text { Routines }\end{array}$ \\
\hline
\end{tabular}

Fig. 1. Characteristics of Organization Design-Routines Fit

To begin, the extent of modularity in organization structure and the degree of businessunit specificity of routines often go together. Routines that have high business-unit specificity support activities that are contained within business units, such as operational auto assembly routines or dynamic drug development routines, independent of the operations of other business units. The converse holds as well. Routines that coordinate activities between units, such as operational routines for internal supply chain coordination or dynamic routines for cross-functional innovation, will have low business-unit specificity and are likely associated with less modularity in organization design. As another example, what is often referred to as the "parenting advantage" of some diversified corporations involves non-business-unit specific operational routines for using consistent financial principles or sourcing inputs from similar vendors (Campbell, Goold, \& Alexander, 1995).

Recall that, as the interdependence across routines and the need for coordination grow, we would expect to see these processes grouped together and the organization to become less modular (Argyres, 1996). This is evident in the commonly observed practice of firms recombining business units (Karim, 2006, 2009). For example, when Johnson \& Johnson $(\mathrm{J} \& \mathrm{~J})$ saw interdependencies across their Arbrook Inc. (which made bandages and disinfection equipment) and Jelco Laboratories (which made syringes, needles, and blood-collection equipment) business units, J\&J chose to group these units together. The company formed Surgikos, Inc. to more effectively use the routines and processes involved in its surgical sterilization businesses (Karim \& Kaul, 2015).

The arguments thus far imply that all else equal, high business-unit specificity of routines is associated with a more modular organization design and vice versa. These arguments hold for both operational and dynamic routines; if the routines in question are specific to a particular business unit, we expect to see a more modular design. Thus, Figure 1 indicates a more modular design in quadrants 2 and 3, which have high business-unit specificity of both operational and dynamic routines. Conversely, quadrants 1 and 4 have low business-unit specificity of routines and a less modular design.

Like modularity in organization design, the extent of top management team involvement 
with the business units depends on the characteristics of routines. As argued earlier, operational routines that are specific to individual business units require relatively little top management team involvement, as indicated in quadrant 2 of Figure 1. Thus, when firms rely on operational routines that have high business-unit specificity, we would expect to see a more modular organization and low top management team involvement in the business units.

Operational routines that facilitate coordination across business units for ongoing operations, such as for internal supply chains, have less business-unit specificity. As indicated earlier, such routines may call for some top management attention to ensure that coordination between business units does not lapse. These routines also are associated with a less modular organizational structure, as indicated in quadrant 1 . Hence, the extent of top management team involvement may be somewhat higher in quadrant 1 than in quadrant 2, where operational routines have high business-unit specificity and the organization design is more modular.

Turning to dynamic routines, the degree of business-unit specificity in these routines affects the extent of involvement required of top management. As noted earlier, when dynamic routines are specific to individual business units, as may occur for drug discovery routines, the extent of top management involvement depends on whether or not top management has relevant expertise. Essentially, the more context-specific and business-unit-specific are the dynamic routines, the less likely is top management involvement. Thus, quadrant 3 indicates relatively low top management involvement for highly business-unit-specific dynamic routines, along with a modular organization design.

In contrast, dynamic routines with low business-unit specificity, such as routines for crossfunctional innovation, support strategic and organizational change that go beyond individual business units. Because changes of this type call for an understanding of the firm as a whole, many such routines inhere in the top management team and the corporate staff. Thus, quadrant 4 indicates greater top management team involvement with business units. This quadrant also indicates a less modular organization design, consistent with low business-unit specificity of routines.

\section{DISCUSSION AND CONCLUSIONS}

The foregoing analysis essentially provides a normative theory in which the effectiveness of organization design and redesign depends on the nature of routines. Figure 1 indicates that when organizations have high business-unit specificity of both operational and dynamic routines, we expect to find a more modular organization design and low involvement of top management in the business units. Understanding that this sort of classic decentralized organization entails high business-unit specificity of routines has important implications for potential changes in organization design. In particular, if an organization combines units that have highly specific routines, this is likely to cause problems because the specificity of the routines will make it difficult for the combined units to coordinate effectively, at least initially.

Turning to organizations with low business-unit specificity of operational routines, we expect to see a less modular organization design and somewhat greater top management involvement. Again, the nature of the routines has implications for changes in organization design. If firms attempt to increase the extent of modularity in organization design, they again are likely to run into problems because the low business-unit specificity of the routines is not well suited to a modular design.

Finally, when organizations have dynamic routines with low business-unit specificity, we expect to see both a less modular organization design and substantial top management involvement. In this situation, organizations that seek to make strategic changes on a regular basis but try to push responsibility for such change further down in the organization are likely to run into trouble because the routines cross functions and businesses. More generally, our analysis implies that if organizations seek to make changes in their organization design, doing so without attention to the specificity of their routines will lead to difficulties.

This analysis holds when an organization is characterized primarily by one quadrant in Figure 1. However, many organizations, especially larger ones, do not fit neatly into just one 
quadrant. For example, companies may have some operational routines with high businessunit specificity that reside within modular business units, as well as some low businessunit-specific routines that are utilized by multiple units (e.g., routines of a shared sales force across an electronics division and an appliance division). Companies may also have both operational routines and dynamic routines with low business-unit specificity, yet the former calls for less top management involvement than the latter. Or companies may have some dynamic routines that have high business-unit specificity (e.g., for drug discovery) and others that have low business-unit specificity (e.g., for new strategic initiatives that span organizational units), which entail different degrees of both top management involvement and organizational modularity. How should firms design their organizations to best fit these multiple demands?

One suggestion is to design multidimensional (i.e., matrix) organizations (Galbraith, 2010). As organizations have entered international markets and diversified into multiple businesses, different units within the organization often serve the same customer. Matrix organizations originated from the demands of customers to interact with one contact (or account team) at the organization that would manage the integration issues seamlessly and "provide integrated packages of products, services, software and most of all, thought leadership" (Galbraith, 2010: 115). Galbraith suggested that matrix organizations have the ability to self-reconfigure as they find new market opportunities, implying that each part within the matrix needs to be highly modular in delivering its product or service, yet there needs to be a significant amount of cross-unit coordination to effectively offer an "integrated package" to the customer. How is this achieved? The key is to have personnel, which Galbraith referred to as "the talent," "selectively moved into cross-company teams" (2010: 115). Building on his ideas, we expect that as firms grow and potentially develop more business-unit-specific routines, firms may design matrix organizations that have a greater number of modules yet rotate their top executives across these modules. The executives each obtain a diversity of experiences and can better coordinate when placed in cross-company leadership teams by viewing issues from multiple perspectives. In this regard, top management serves as the glue within the organization, having learned from multiple experiences across the firm and able to relate to the challenges faced by leaders of different parts of the organization (Galbraith, 2010). This design has strong implications for managerial career paths as we see that executives' development of their own human capital may determine the opportunities available to them (Karim \& Williams, 2012).

Another solution involves creating "dual structures" (Duncan, 1976) where some business units (with more operational routines) focus on maintaining the status quo, whereas others (with more dynamic routines) focus on adaptation and new market opportunities; this is what Gibson and Birkinshaw (2004) refer to as "structural ambidexterity." In this approach, top management decides whether to create new business units to pursue new ideas, and provides financial and organizational support for these units (O'Reilly \& Tushman, 2008). Here the dynamic routines of top management, which have low business-unit specificity, work alongside the business-unit-specific operational routines of ongoing businesses and the business-unit-specific dynamic routines of new businesses.

Alternatively, business units that are able to achieve both alignment and adaptability have the trait of "contextual ambidexterity"; this is best achieved "not through the creation of dual structures, but by building a set of processes or systems that enable and encourage individuals to make their own judgments about how to divide their time between conflicting demands for alignment and adaptability" (Gibson \& Birkinshaw, 2004: 210). A design of contextually ambidextrous business units emerges when leaders can "develop a supportive organization context" (Gibson \& Birkinshaw, 2004: 210). This design, and specifically its degree of decentralization, likely depends on how tasks are allocated within units and the extent to which individuals have formal authority over their work (Dobrajska, Billinger, \& Karim, 2014). Our analysis suggests additional implications. In particular, contextual ambidexterity implies that a single business unit has both operational and dynamic routines. As shown in Figure 1, the degree of modularity and top management involvement for these two types of routines is the same only when the routines are highly business-unit-specific. Thus, consistent with quadrants 2 and 3 of the figure, we expect to see contextual ambidexterity associated 
with a high level of autonomy and a more modular design, along with high business-unit specificity of both operational and dynamic routines.

Despite the potential for organizations to develop designs that can accommodate business units that have routines with different degrees of business-unit specificity and operational versus dynamic purposes, we know that matrix organizations and ambidextrous structures are difficult to manage well. Thus, for firms that do not clearly fit into one of the four quadrants in our framework, more attention is warranted to organizational leadership and career paths, coordination across business units, and allocation of work so that the nature of routines and the design of the organization are aligned.

Acknowledgments: We would like to thank Phanish Puranam for his very helpful feedback and suggestions. Any errors remain our own.

\section{REFERENCES}

Alexander C. 1964. Notes on the Synthesis of Form. Harvard University Press, Cambridge, MA.

Amit R, Schoemaker PJH. 1993. Strategic assets and organizational rent. Strategic Management Journal 14(1): 33-46.

Argote L. 1999. Organizational Learning: Creating, Retaining and Transferring Knowledge. Springer, New York, NY.

Argyres NS. 1996. Capabilities, technological diversification and divisionalization. Strategic Management Journal 17: 395-410.

Baldwin CY, Clark KB. 2000. The Power of Modularity. The MIT Press, Cambridge, MA.

Barney J. 1991. Firm resources and sustained advantage. Journal of Management 17(1): 99-120.

Becker MC. 2004. Organizational routines: A review of the literature. Industrial and Corporate Change 13(4): 643-678.

Campbell A, Goold M, Alexander M. 1995 Corporate strategy: The quest for parenting advantage. Harvard Business Review 73(2): 120-132.

Chandler AD. 1962. Strategy and Structure: Chapters in the History of the American Industrial Enterprise. Doubleday Books, New York, NY.

Collis DJ. 1994. How valuable are organizational capabilities? Strategic Management Journal 15(S1): 143-152.

Duncan R. 1976. The ambidextrous organization: Designing dual structures for innovation. In R.H. Killman, L.R. Pondy, and D. Sleven (Eds.), The Management of Organization: 167-188. North Holland, NY.

Dobrajska M, Billinger S, Karim S. 2014. Decentralization of formal and real decision authority: An empirical investigation. Working paper, Boston University.

Feldman MS, Pentland BT. 2003. Reconceptualizing organizational routines as a source of flexibility and change. Administrative Science Quarterly 48(1): 94-118.

Galbraith JR. 1977. Organization Design: An Information Processing View. Addison-Wesley, Reading, MA.

Galbraith JR. 2010. The multi-dimensional and reconfigurable organization. Organizational Dynamics 39(2): 115-125.

Galbraith JR, Kazanjian RK. 1986. Strategy Implementation: Structure, Systems and Process. West Publishing, St. Paul, MN.

Galunic DC, Eisenhardt KM. 1996. The evolution of intracorporate domains: Divisional charter losses in high-technology, multidivisional corporations. Organization Science 7(3): 255-282.

Galunic DC, Eisenhardt KM. 2001. Architectural innovation and modular corporate forms. Academy of Management Journal 44(6): 1229-1249.

Gibson CB, Birkinshaw J. 2004. The antecedents, consequences and mediating role of organizational ambidexterity. Academy of Management Journal (47): 209-226.

Hannan MT, Freeman J. 1989. Organizational Ecology. Harvard University Press, Cambridge, MA. 
Helfat CE. 1994. Evolutionary trajectories in petroleum firm R\&D. Management Science 40(12): 1720-1747.

Helfat CE, Finkelstein S, Mitchell W, Peteraf M, Singh H, Teece D, Winter SG. 2007. Dynamic Capabilities: Understanding Strategic Change in Organizations. Blackwell Publishing, Malden, MA.

Helfat CE, Winter SG. 2011. Untangling dynamic and operational capabilities: Strategy for a (n)ever-changing world. Strategic Management Journal 32(11): 1243-1250.

Hill CWL, Hitt MA, Hoskisson RE. 1992. Cooperative versus competitive structures in related and unrelated diversified firms. Organization Science 3(4): 501-521.

Karim S. 2006. Modularity in organizational structure: The reconfiguration of internally developed and acquired business units. Strategic Management Journal 27(9): 799-823.

Karim S. 2009. Business unit reorganization and innovation in new product markets. Management Science 55(7): 1237-1254.

Karim S. 2012. Exploring structural embeddedness of product market activities and resources within business units. Strategic Organization 10(4): 333-365.

Karim S, Kaul A. Forthcoming 2015. Structural recombination and innovation: Unlocking intra-organizational knowledge synergy through structural change. Organization Science.

Karim S, Williams C. 2012. Structural knowledge: How executive experience with structural composition affects intrafirm mobility and unit reconfiguration. Strategic Management Journal 33(6): 681-709.

Kauffman SA. 1991. Antichaos and adaptation. Scientific American 265(2): 78-84.

Kauffman SA. 1992. The Origins of Order. Oxford University Press, Oxford, UK.

Lawrence PR, Lorsch JW. 1967. Differentiation and integration in complex organizations. Administrative Science Quarterly 12(1): 1-47.

March JG, Simon HA. 1958. Organizations. Wiley, New York, NY.

McGahan AM, Porter ME. 1997. How much does industry matter really? Strategic Management Journal 18: 15-30.

Michel JG, Hambrick DC. 1992. Diversification posture and top management team characteristics. Academy of Management Journal 35(1): 9-37.

Mintzberg H. 1979. The Structuring of Organizations: A Synthesis of the Research. PrenticeHall, Englewood Cliffs, NJ.

Murmann JP, Aldrich HE, Levinthal D, Winter SG. 2003. Evolutionary thought in management and organization theory at the beginning of the new millennium. Journal of Management Inquiry 12(1): 22-40.

Nadler D, Tushman ML. 1997. Competing by Design: The Power of Organizational Architecture. Oxford University Press, New York, NY.

Nelson RR, Winter SG. 1982. An Evolutionary Theory of Economic Change. Belknap/ Harvard University Press, Cambridge, MA.

O'Reilly CA, Tushman ML. 2008. Ambidexterity as a dynamic capability: Resolving the innovator's dilemma. Research in Organizational Behavior 28: 185-206.

Pentland BT, Feldman MS. 2005. Organizational routines as a unit of analysis. Industrial and Corporate Change 14(5): 793-815.

Rumelt RP. 1974. Strategy, Structure and Economic Performance in Large Industrial Organizations. Harvard Business School Press, Boston, MA.

Rumelt RP. 1991. How much does industry matter? Strategic Management Journal 12(3): 167-185.

Sanchez R, Mahoney JT. 1996. Modularity, flexibility and knowledge management in product and organization design. Strategic Management Journal 17(winter special issue): 63-76.

Schilling MA. 2000. Towards a general modular systems theory and its application to interfirm product modularity. Academy of Management Review 25: 312-334.

Simon HA. 1996. The Sciences of the Artificial (3rd ed.). The MIT Press, Cambridge, MA.

Szulanski G. 1996. Exploring internal stickiness: Impediments to the transfer of best practices within the firm. Strategic Management Journal 17(special issue): 27-43.

Szulanski G. 2003. Sticky Knowledge: Barriers to Knowing in the Firm. Sage Publications, Thousand Oaks, CA.

Thompson JD. 1967. Organizations in Action: Social Science Bases of Administrative 
Theory. McGraw-Hill, New York, NY.

Weick KE. 1976. Educational organizations as loosely coupled systems. Administrative Science Quarterly 21:1-19.

Williamson OE. 1985. The Economic Institutions of Capitalism. Free Press, New York, NY. Winter SG. 1987. Knowledge and competence as strategic assets. In D.J. Teece (Ed.), The Competitive Challenge: Strategies for Industrial Innovation and Renewal. Ballinger, Cambridge, MA.

Winter SG. 2003. Understanding dynamic capabilities. Strategic Management Journal 24(10): 991-995.

Zollo M, Winter SG. 2002. Deliberate learning and the evolution of dynamic capabilities. Organization Science 13(3): 339-351.

\section{CONSTANCE E. HELFAT}

J. Brian Quinn Professor in Technology and Strategy

Tuck School of Business at Dartmouth

E-mail: constance.helfat@dartmouth.edu

\section{SAMINA KARIM}

Associate Professor

Boston University

E-mail: samina@bu.edu 